\title{
Restituting intestinal epithelial cells exhibit increased transducibility by adenoviral vectors
}

\author{
Filippos Kesisoglou ${ }^{1}$ \\ Phyllissa Schmiedlin-Ren ${ }^{2}$ \\ David Fleisher ${ }^{1}$ \\ Blake Roessler ${ }^{3}$ \\ Ellen M. Zimmermann ${ }^{2 *}$ \\ ${ }^{1}$ Department of Pharmaceutical \\ Sciences, College of Pharmacy, The \\ University of Michigan, Ann Arbor, \\ MI 48109-1065, USA \\ ${ }^{2}$ Division of Gastroenterology, \\ Department of Internal Medicine, The \\ University of Michigan, Ann Arbor, \\ MI 48109-0682, USA \\ ${ }^{3}$ Division of Rheumatology, \\ Department of Internal Medicine, The \\ University of Michigan, Ann Arbor, \\ MI 48109-0688, USA \\ *Correspondence to: \\ Ellen M. Zimmermann, The \\ University of Michigan, Division of \\ Gastroenterology, Department of \\ Internal Medicine, 6520 MSRB I, \\ Ann Arbor, MI 48109-0682, USA. \\ E-mail: ezimmer@umich.edu
}

\begin{abstract}
Background and aims While mature enterocytes are resistant to transduction by adenovirus type 5 (Ad5) vectors, undifferentiated cells are transduced much more efficiently. Our purpose was to study enterocyte transduction in models of intestinal wound healing.

Methods Transduction was studied ex vivo using cultures of endoscopic biopsies and in vitro utilizing Caco- 2 cells in models of mucosal wound healing. Vectors carried either the LacZ or the luciferase gene. CAR (coxsackievirus and adenovirus receptor) and integrins were studied with transduction inhibition and immunofluorescent staining.

Results Increased transduction efficiency was observed for a subset of enterocytes with a flattened de-differentiated phenotype present at the edge of cultured biopsies. In the in vitro systems, expanding Caco- 2 cell monolayers exhibited increased transducibility that was time- and dosedependent, reaching virtually $100 \%$ in cells along the leading edge at high viral load. Bioluminescence activity of transduced expanding monolayers was up to 3-fold greater than that of non-expanding monolayers ('fence' system, $48 \mathrm{~h}$, MOI 1000, $p<0.05$ ). Mitomycin C pre-treatment did not affect levels of transduction in expanding monolayers. At the highest viral load tested, CAR or integrin blocking prior to virus application resulted in $39.4 \%$ and $45.4 \%$ reduction in transduction levels $(p<0.05)$. Immunofluorescence revealed altered expression of CAR on the migrating edge of the Caco- 2 cultures and the expression of CAR on the apical membrane of biopsy enterocytes.
\end{abstract}

Conclusions Increased CAR and integrin accessibility in migrating enterocytes mediates increased transduction by Ad5 vectors. This subset of enterocytes provides a target for the delivery of genes of interest for both research and gene therapy applications. Copyright (c) 2006 John Wiley \& Sons, Ltd.

Keywords Caco-2 cells; wound healing; coxsackievirus and adenovirus receptor; adenovirus; enterocytes; inflammatory bowel disease

\section{Introduction}

Adenoviruses are valuable gene delivery vectors for manipulation of cellular genes/processes, for both research applications and gene therapy strategies. Adenoviruses are naturally responsible for human respiratory and gastrointestinal infections [1], suggesting that epithelial cells may be possible targets for recombinant adenoviral vectors. The intestinal epithelium itself presents several advantages as a gene delivery target, 
such as ease of access via the lumenal route, large tissue mass, increased numbers of rapidly proliferating cells, and access to epithelial stem cells located in the crypts of Lieberkuhn $[2,3]$. Local expression of the transgene could prove particularly advantageous for studying or treating gastrointestinal diseases originating in the intestinal wall such as inflammatory bowel disease and colon cancer.

One of the major obstacles to utilizing recombinant adenoviruses for gastrointestinal gene delivery is the relatively low transduction efficiency of mature intestinal epithelial cells by adenoviral vectors as seen both in vitro [4-6] and in vivo [2-4,7]. In vitro studies showed that transduction efficiency of enterocytes was concentrationdependent and inversely correlated with degree of differentiation and cell density [2,4-6]. In the case of Caco- 2 cells, a human colorectal adenocarcinoma cell line that undergoes spontaneous enterocytic differentiation in culture [8] and is extensively used as a model of small intestinal epithelium, transduction efficiency dramatically decreased after 3 days in culture when cells began to differentiate $[5,6]$. Well-differentiated Caco2 cells that had been more than 2 weeks in culture exhibited extremely low transducibility [5,6]. IEC-18 cells, which represent a less differentiated crypt celllike phenotype, were transduced more readily [4]. The difference in transduction efficiency at the different stages of differentiation has been partly attributed to the fact that $\alpha_{\nu}$-integrins, known to facilitate the adenovirus internalization process, are more accessible to the virus on the apical membrane in the early stages of differentiation [4,5]. In vivo studies further confirmed that integrin expression significantly affected gene transfer to the intestinal epithelium [4,9]. As a result, adenoviral gene delivery to the intestine seems more promising if targeted towards less well-differentiated cells or in cases where epithelial integrity has been impaired.

Restituting intestinal epithelial cells have been shown to exhibit a less well-differentiated phenotype [10] and therefore could be more susceptible to transduction by adenoviral vectors. Utilizing an ex vivo culture system of intestinal biopsies obtained at the time of endoscopy, we observed increased transduction efficiency for a subset of enterocytes with a flattened de-differentiated phenotype, present at the edges of the biopsy. This is the first demonstration of increased transduction of restituting epithelial cells in human tissue. To mimic in vitro the intestinal damage and mucosal wound healing conditions, we used two well-established in vitro models of restituting epithelium and studied differences in adenoviral transduction efficiency between migrating and non-migrating cells. We further carried out transduction inhibition and immunofluorescence experiments to study the role of integrins and CAR (coxsackievirus and adenovirus receptor) in mediating increased transduction in the migrating Caco- 2 cells. Differences in CAR expression were observed between migrating and confluent Caco- 2 cells. Apically accessible CAR appears to be mediating the transduction of migrating Caco-2 cells. This is in contrast to other epithelial cell models such as airway epithelium where basolaterally localized CAR appears to mediate adenoviral transduction [11].

\section{Materials and methods}

\section{Materials}

Tissue culture reagents were obtained from Invitrogen Co. (Carlsbad, CA, USA) and tissue culture materials were from Becton Dickinson (Franklin Lakes, NJ, USA) and Corning Inc. Life Sciences (Acton, MA, USA). The GRGDSP RGD peptide was purchased from Bachem AG (King of Prussia, PA, USA). All other chemicals used were of analytical grade and purchased from Sigma (St. Louis, MO, USA) and Fisher Scientific (Pittsburgh, PA, USA).

\section{Human subjects}

These studies were approved by the Institutional Review Board of the University of Michigan Medical Center (IRBMED \#1998-0016). All subjects gave informed consent. Endoscopic biopsies from the second portion of the duodenum were obtained from patients undergoing esophagogastroduodenoscopy for clinical indications but whose duodeni appeared endoscopically normal. Exclusion criteria were: age less than 18 years or greater than 65 years, known HIV or viral hepatitis, coagulopathy, use of anticoagulants such as aspirin or coumadin, or inability to give informed consent. Two to six biopsies were obtained from each of seven subjects.

\section{Adenoviral vectors}

Adenoviral type 5 (Ad5) vectors (Vector Core Laboratory, University of Michigan) were used for all experiments. Ad5CMV-luc and Ad5CMV-luc(loxP) vectors contained the luciferase reporter gene in the $\mathrm{E} 1 \mathrm{~A} / \mathrm{E} 1 \mathrm{~B}$ region of the viral genome under the control of the cytomegalovirus (CMV) promoter [12]. Ad5CMV-betaGal contained the nuclear targeted beta-galactosidase ( $L a c Z$ ) gene. For the modified Ad5SHORT vectors the endogenous Ad5 fiber gene was replaced by the Ad41 short fiber gene. The Ad5SHORT-luc vector is analogous to Ad5CMV-luc(loxP). Ad5SHORT vectors were produced by homologous recombination in $E$. coli BJ5183 recBC sbcBC $[13,14]$.

\section{Explant culture and transduction}

Biopsies from endoscopically normal duodenum were placed in organ culture as previously described [15] with minor modifications. Explant culture medium consisted of 8 parts CMRL medium 1066 (Gibco BRL, Grand Island, NY, USA) combined with 2 parts F-12 (Ham) nutrient 
mixture (Gibco BRL), and then supplemented to the indicated final concentrations with the following: fetal bovine serum (FBS, 10\%; Hyclone, Logan, UT, USA); glucose (10 mM; Abbott Laboratories, N. Chicago, IL, USA); GlutaMax I (2 mM; Gibco BRL); sodium selenite (0.1 $\mu \mathrm{M}$; Sigma); zinc sulfate ( $3 \mu \mathrm{M}$; Sigma); menadione sodium bisulfite (145 nM; Sigma); vitamin E acetate (45 nM; Sigma or Gibco); sodium penicillin G (100 $\mathrm{U} / \mathrm{ml}$; Gibco BRL); and gentamicin (50 $\mu \mathrm{g} / \mathrm{ml}$; Sigma). All components used to supplement the medium were of cell culture quality. Sterile normal saline was placed in the outer well of each organ culture dish to ensure adequate humidity.

Biopsies were transferred from the endoscopic biopsy forceps into sterile transport medium [80\% CMRL medium 1066, 20\% F-12 (Ham) nutrient mixture] that had been pre-equilibrated with $5 \% \mathrm{CO}_{2}$ in oxygen and kept on ice. After immediate transport to the laboratory, each biopsy was oriented lumenal-side up (with the aid of a dissecting microscope) on a stainless steel screen in an organ culture dish (Falcon, Oxnard, CA, USA) containing $2.15 \mathrm{ml}$ of explant culture medium pre-equilibrated with $5 \% \mathrm{CO}_{2}$ in oxygen. The explants were only partially submerged in this volume of medium. In the biological safety cabinet, $4 \mu \mathrm{l}$ of a suspension containing $4 \times 10^{11}$ particles Ad5CMV-betaGal/ml were applied directly to the upper surface of each explant $\left(1.6 \times 10^{9}\right.$ particles per explant). At least two biopsies per patient were used for transduction experiments which were performed on separate occasions on biopsies from seven patients. In preliminary experiments, cultured biopsies (explants) were evaluated for structural integrity and were found to maintain near normal morphology for up to $45 \mathrm{~h}$ with identifiable microvilli and tight junctions. Exposure to vectors during the culture period did not affect tissue morphology [16].

The dishes were then placed on the rack of a modular incubator chamber (Billups Rothenberg Incorporated, Del Mar, CA, USA); open dishes containing water were placed below the rack for humidification. The chamber was gassed with approximately 10 volumes of $5 \% \mathrm{CO}_{2}$ in oxygen over $15 \mathrm{~min}$, then sealed and placed on a rotating table in a $37^{\circ} \mathrm{C}$ incubator. The rotating table was turned on (at $40 \mathrm{rpm}$ ) $2 \mathrm{~h}$ after the application of the vector. The start of gassing occurred approximately 45-60 min from the start of biopsy procurement and was considered $0 \mathrm{~h}$. Explants were kept in culture for 24-28 $\mathrm{h}$ at which point transduction was assayed by $\mathrm{X}-\mathrm{Gal}$ staining.

\section{Cell culture}

Caco-2 cells (ATCC HTB37) of passage 33-44 were maintained in Dulbecco's modified Eagle's medium (DMEM) supplemented with $20 \%$ heat-inactivated FBS, $0.1 \mathrm{mM}$ non-essential amino acids (NEAA), $45 \mathrm{nM}$ vitamin $\mathrm{E}$, 100 units $/ \mathrm{ml}$ penicillin, and $100 \mu \mathrm{g} / \mathrm{ml}$ streptomycin until confluent (typically 3 days). Medium was changed to DMEM with 5\% FBS, $0.1 \mathrm{mM}$ NEAA, $45 \mathrm{nM}$ vitamin E, $0.1 \mu \mathrm{M}$ selenium $\left(\mathrm{Na}_{2} \mathrm{SeO}_{3}\right), 0.003 \mathrm{nM}$ zinc $\left(\mathrm{ZnSO}_{4} \cdot 7 \mathrm{H}_{2} \mathrm{O}\right), 100$ units $/ \mathrm{ml}$ penicillin, and $100 \mu \mathrm{g} / \mathrm{ml}$ streptomycin until the end of the experiment (typically 2 weeks). Cells were grown at $37^{\circ} \mathrm{C}$ in an atmosphere of $5 \% \quad \mathrm{CO}_{2}$ and $90 \%$ relative humidity.

\section{Adenoviral infection studies in the wounded monolayer system}

Caco- 2 cells were seeded at a density of $4 \times 10^{5}$ cells/well on porous collagen-coated polycarbonate cell culture inserts with a pore size of $1 \mu \mathrm{m}$ and a surface area of $0.9 \mathrm{~cm}^{2}$ (Corning Inc. Life Sciences) in 12-well plates. Medium was changed every other day for 2 weeks in both apical and basolateral chambers. Differentiated monolayers were mechanically wounded by cutting the monolayer with a cell scraper along one diameter of the insert. Cells were washed with DMEM to remove cell debris and feeding medium was added to both apical and basolateral chambers. Cells were kept in culture for up to $48 \mathrm{~h}$ to allow for wound healing to occur. Basolateral medium was renewed while apical medium was replaced with medium containing the desired adenoviral vector(s) at a MOI (multiplicity of infection) of 10, 100, and 1000. After a $2 \mathrm{~h}$ incubation at $37^{\circ} \mathrm{C}$, an equal amount of medium was added to the apical chamber and cultures were incubated for 24 or $48 \mathrm{~h}$ at $37^{\circ} \mathrm{C}$. At this time, beta-galactosidase expression was assayed with $\mathrm{X}-\mathrm{Gal}$ staining while luciferase expression was assayed by bioluminescence imaging.

\section{Adenoviral infection studies in the 'fence' system}

Caco-2 cells were seeded at a density of $3.33 \times 10^{5}$ cells/well in the central opening of stainless steel rings ('fences') placed with the help of an O-ring in the center of the wells of 6-well culture plates or $35 \mathrm{~mm}$ culture dishes ('fences' kindly provided by Dr. Jerrold R. Turner, University of Chicago). Cell growth area was $0.79 \mathrm{~cm}^{2}$ and the volume of cell suspension used was $500 \mu \mathrm{l}$. Medium was changed every other day until cells reached a differentiated state. At this point, the 'fence' was removed and new medium was added. Radial monolayer expansion occurs when the 'fence' is lifted from the culture plate [17]. Monolayer expansion was allowed to take place for $24 \mathrm{~h}$ after which medium was replaced with adenovirus-containing medium (Ad5CMV or Ad5SHORT; 10, 100 and 1000 MOI). Subsequent steps were similar to the wounded monolayer system. In some studies (conducted at the intermediate MOI of 200), proliferation was first blocked by pre-treatment of the monolayers with $20 \mu \mathrm{g} / \mathrm{ml}$ mitomycin C (Sigma) for $2 \mathrm{~h}$ prior to fence removal. This mitomycin $\mathrm{C}$ concentration has been shown to be sufficient to arrest cell proliferation in Caco-2 cell cultures $[18,19]$. 


\section{Adenoviral infection studies in differentiated Caco-2 cells}

Caco- 2 cells were seeded at a density of $4 \times 10^{5}$ cells/well on porous collagen-coated polycarbonate cell culture inserts with a pore size of $1 \mu \mathrm{m}$ and a surface area of $0.9 \mathrm{~cm}^{2}$ in 12 -well plates. Medium was changed every other day for 2 weeks in both apical and basolateral chambers. Differentiated Caco-2 monolayers were infected with the Ad5CMV-luc(loxP) vector at the desired MOI, either apically or basolaterally. Basolateral transduction was carried out by inverting the culture inserts. Adenovirus transduction was allowed to proceed for $2 \mathrm{~h}$ at $37^{\circ} \mathrm{C}$ at which point medium was aspirated, replenished with fresh medium, and cells were returned to the incubator. Luminescence activity was assayed after $48 \mathrm{~h}$. In a separate set of experiments, differentiated Caco-2 monolayers were treated with $2.5 \mathrm{mM}$ ethylene glycol tetraacetic acid (EGTA) added to both apical and basolateral chambers for $45 \mathrm{~min}$ at $37^{\circ} \mathrm{C}$. This concentration of EGTA has been previously reported to be sufficient to widen the tight junctions in Caco-2 cells [20,21]. Tight junction widening was confirmed in our studies by a decrease in transepithelial electrical resistance measurements before and after EGTA treatment. Adenoviral infection was subsequently carried out as described above.

\section{X-Gal staining}

At the end of the culture period, explants were fixed in $2 \%$ formalin in phosphate-buffered saline (PBS) for $2 \mathrm{~h}$, washed twice for $5 \mathrm{~min}$ in PBS containing $2 \mathrm{mM}$ magnesium chloride, and placed in X-Gal staining solution $[1 \mathrm{mg} / \mathrm{ml}$ X-Gal (5-bromo-4-chloro-3-indolyl$\beta$-D-galactoside), $5 \mathrm{mM}$ potassium ferricyanide, $5 \mathrm{mM}$ potassium ferrocyanide, $2 \mathrm{mM}$ magnesium chloride, $0.01 \%$ sodium deoxycholate, $0.02 \%$ Nonidet P-40] at $33^{\circ} \mathrm{C}$ for $16-18 \mathrm{~h}$. The tissue was then washed twice in PBS and post-fixed in 10\% neutral buffered formalin. After $2 \mathrm{~h}$ in $10 \%$ formalin, the tissue was placed in $30 \%$ sucrose $10 \%$ formalin for an additional $24 \mathrm{~h}$, then embedded in O.C.T. compound (Miles Inc., Elkhart, IN, USA) and frozen at $-80^{\circ} \mathrm{C}$. All steps prior to embedding were carried out on a rotating table at 40-60 rpm.

\section{Sectioning and counterstaining}

Sections of the O.C.T.-embedded tissue were prepared with a cryostat and stored at $-80^{\circ} \mathrm{C}$. Rehydrated sections of the X-Gal-stained tissue were counterstained with $0.1 \%$ Nuclear Fast Red (Sigma; C.I. 60760) in 5\% aluminum sulfate, then dehydrated through a graded series of ethanol, cleared in xylene, and coverslipped with Permount (Fisher Scientific).

\section{Quantitation of X-Gal-stained nuclei}

Without magnification, five sections without evidence of folds were chosen from near the center of each explant as judged by largest section size. Consecutive sections were avoided. The morphology of the enterocytes in each section was evaluated microscopically; the presence or absence of columnar enterocytes and attenuated enterocytes (at tissue edges or extending beneath the tissue as a monolayer) was recorded. Note was made of the presence or absence of transduced cells within these subpopulations of enterocytes.

\section{Bioluminescence imaging}

At the end of the desired virus incubation time, medium was replaced with feeding medium containing 0.15 or $0.4 \mathrm{mg} / \mathrm{ml}$ luciferin and incubated for $30 \mathrm{~min}$ at $37^{\circ} \mathrm{C}$. Luciferase expression was quantified as bioluminescence photon counts using a cryogenically cooled Xenogen IVIS $^{\mathrm{TM}}$ Imaging system (Xenogen Corporation, Alameda, CA, USA) coupled to a data acquisition computer at the Center for Molecular Imaging, University of Michigan. A digital grayscale image was acquired followed by acquisition and overlay of a pseudocolor image representing the spatial distribution of detected photon counts emerging from active luciferase within the wells. Signal intensity was quantified as the sum of all detected photons within the region of interest during a 1 or 3 min luminescent integration time, at level B. Results were expressed as fold photon counts compared to untransduced cells present in the plate.

\section{Adenoviral infection inhibition studies}

A mouse monoclonal antibody against human CAR was produced by the Hybridoma Core, University of Michigan, from a commercially available clone (ATCC \#CRL2379) [22]. Infection inhibition studies were carried out using the 'fence' system. Twenty-four hours after 'fence' removal, medium was replaced with blocking medium containing either the monoclonal anti-CAR antibody (ascites fluid 1:50, tissue culture supernatant $1: 1$ ) or an RGD peptide (GRGDSP; $0.4 \mathrm{mM}$ or $1 \mathrm{mM}$ ) that blocks integrin binding [4]. Monolayers were incubated with blocking medium for $2 \mathrm{~h}$ at room temperature under gentle rotation. Blocking medium was replaced by medium containing the desired MOI of adenoviral vector(s) and plates were moved to the $37^{\circ} \mathrm{C}$ incubator to allow for virus infection to occur. After $2 \mathrm{~h}$, vectorcontaining medium was replaced with fresh medium and culture was continued for $48 \mathrm{~h}$ before assessing transduction efficiency. The studies were carried out at the submaximal MOI of 200 and at the high MOI of 1000. The two RGD peptide concentrations of $0.4 \mathrm{mM}$ and $1 \mathrm{mM}$ were chosen based on results published on integrinbinding inhibition in differentiated and undifferentiated Caco-2 cells [4]. 


\section{Immunofluorescent detection of CAR and cytokeratin}

Intestinal explants were stained for cytokeratin and CAR. For cytokeratin staining, archived sections of explants ( $48 \mathrm{~h}$ culture), which had been fixed in 10\% neutral buffered formalin for $>24 \mathrm{~h}$ and embedded in paraffin, were deparaffinized and rehydrated through a graded series of ethanol, then subjected to digestion with pepsin (Zymed, South San Francisco, CA, USA) for $10 \mathrm{~min}$ at $37^{\circ} \mathrm{C}$. After washing in PBS, non-specific binding sites were blocked using 2\% chicken serum, 1\% bovine serum albumin (BSA), $0.1 \%$ cold fish skin gelatin, and $0.05 \%$ Tween 20 in PBS containing $0.05 \%$ sodium azide. The blocking solution was decanted from the sections; then mouse anti-cytokeratin 8 \& 18 (Zymed) or MOPC 21 isotype control (both at $5 \mu \mathrm{g} / \mathrm{ml}$ ) was applied and incubated for $1 \mathrm{~h}$ at room temperature. For CAR staining, sections of explants which had been fixed in 4\% paraformaldehyde in PBS for $1 \mathrm{~h}$ and embedded in paraffin after infiltration for $2 \mathrm{~h}$ at $60^{\circ} \mathrm{C}$ were deparaffinized and rehydrated through a graded series of ethanol, then subjected to digestion with proteinase $\mathrm{K}$ (Zymed) for $10 \mathrm{~min}$ at $37^{\circ} \mathrm{C}$. After washing, ImageiT FX signal enhancer (Molecular Probes, Eugene, OR, USA) was applied for $30 \mathrm{~min}$ at room temperature. The sections were again washed and then non-specific binding sites were blocked by incubating with $5 \%$ normal chicken serum for $30 \mathrm{~min}$ at $37^{\circ} \mathrm{C}$. After a single wash in PBS, sections were incubated with anti-CAR (Upstate Cell Signaling Solutions, Lake Placid, NY, USA) or MOPC 21 isotype control (both at $5 \mu \mathrm{g} / \mathrm{ml}$ in $1 \%$ chicken serum in PBS) for $1 \mathrm{~h}$ at $37^{\circ} \mathrm{C}$. After washing in PBS, AlexaFluor 488-labeled chicken anti-mouse IgG (1:100; Molecular Probes) was applied and incubated for $30 \mathrm{~min}$ at room temperature. After washing in PBS, coverslips were applied using ProLong Gold anti-fade mounting medium (Molecular Probes).

For the 'fence' system, 'fences' were placed on top of collagen-coated glass coverslips (Becton Dickinson) placed in 6-well culture plates. Caco-2 cell culture was done as described above for the 'fence' system. Cells were washed with PBS and fixed with 3\% paraformaldehyde prior to immunofluorescence staining. In some cases, cells were permeabilized by applying $0.2 \%$ Triton X-100 for $15 \mathrm{~min}$. Cells were rinsed with PBS, then blocked with $10 \%$ goat serum in PBS for $20 \mathrm{~min}$. Primary antibody was applied (anti-CAR, ascites fluid 1:50) for $1-3 \mathrm{~h}$ at room temperature. Cells were washed twice with PBS, then fluorescein isothiocyanate (FITC) or AlexaFluor 488 conjugated donkey or goat anti-mouse IgG secondary antibody in $10 \%$ goat serum was applied ( $1: 100$ dilution). Cells were incubated in the dark for $1 \mathrm{~h}$ at room temperature. Cells were rinsed twice with PBS, and the coverslips were mounted on glass slides using ProLong mounting medium. Cells were imaged with a Leitz Aristoplan light microscope fitted with a fluorescence filter and equipped with a Diagnostics Spot-RT cooled CCD digital camera.

\section{Data analysis}

Statistical significance was determined using Student's t test. $p$ values less than 0.05 were considered statistically significant. Data are shown as mean \pm standard error of the mean (SEM).

\section{Results \\ Adenoviral transduction of intestinal explants}

We observed the presence of shortened enterocytes at the edges of several explants (Figure 1) occasionally also extending as a monolayer along the bottom of the tissue. The epithelial lineage of the cuboidal cells observed along the bottoms of some explants was confirmed by immunofluorescent staining for cytokeratin (Figure 1d). These shortened epithelial cells at the tissue edges were noted to be transduced more frequently by Ad5CMV-betaGal than were normal columnar enterocytes (Figures 1a-1c).

Columnar epithelial cells were present in all five sections examined from each explant (total 7 subjects, 17 explants, 85 sections); transduction of columnar epithelial cells was observed in four sections (5\% of the 85 total occurrences of columnar epithelial cells), representing 3 of the 17 explants and 2 of the 7 subjects. Attenuated (cuboidal to squamoid) epithelial cells were present at explant edges in at least one explant from each of the seven subjects (12 of 17 total explants; 54 of the 85 total sections examined); transduction of attenuated cells at explant edges was observed in at least one section from five of the seven subjects [total of $14(26 \%)$ of the 54 occurrences; total of 6 of the 12 explants in which the morphology was observed]. These attenuated epithelial cells were noted to extend as monolayers beneath at least one explant from five of the seven subjects ( 8 of 17 total explants; 31 of the 85 total sections examined); transduction of these monolayer cells was observed in explants from three of the five subjects in which monolayer formation was observed [total of 8 (26\%) of the 31 occurrences; total of 3 of the 8 explants in which such a monolayer was observed].

\section{Adenoviral transduction in the wounded monolayer system}

We compared the transduction efficiency of Ad5CMVbetaGal in repairing (wounded) and non-repairing (nonwounded) Caco-2 cell monolayers. Transduction in the confluent non-wounded monolayers, and in the confluent areas of the wounded monolayers, was low, consistent with prior studies [4,5]. Migrating (repairing) cells in the wounded monolayers expressed much higher levels of the $L a c Z$ reporter gene compared to confluent cultures (Figure 2a). Transduction increased with time and dose 

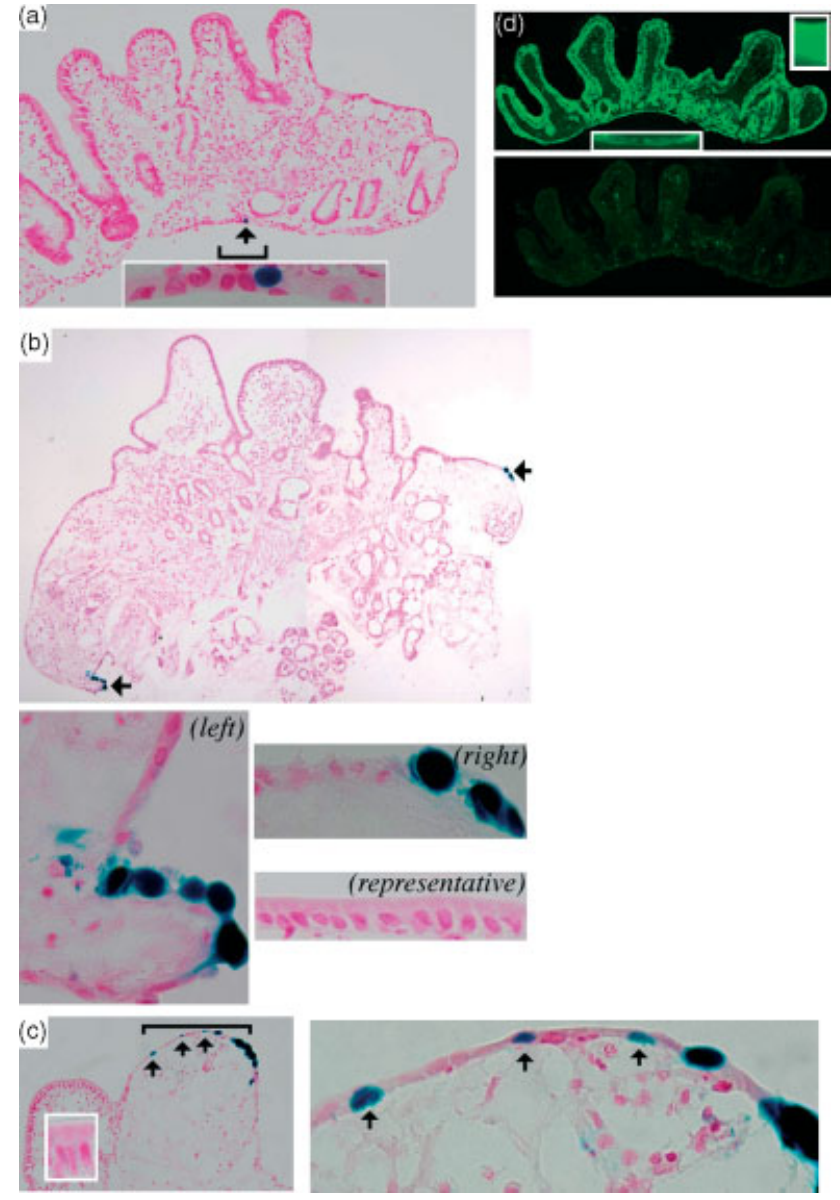

Figure 1. Endoscopic biopsies from the second portion of the duodenum were obtained from patients undergoing esophagogastroduodenoscopy for clinical indications with endoscopically normal mucosa. The biopsies were kept in explant culture for 27-28 $\mathrm{h}$ and exposed to Ad5CMV-betaGal (applied apically at the start of culturing) throughout the culture period. The explants were then fixed and stained en bloc with X-Gal. Sections of the fixed tissue were counterstained with Nuclear Fast Red. X-Gal-stained, i.e. transduced, nuclei appear black. (a) Epithelial cells at the edge of the tissue are shortened and extend as a monolayer across a portion of the bottom of the explant; $x 10$. A single transduced nucleus (arrow) is seen within this monolayer. Inset is $\times 100$ of the bracketed region. (b) Transduced nuclei (arrows) are present among the shortened epithelial cells at each end of the explant; $\times 10$. The lower images are $\times 100$ of the left and right ends of the explant and a representative region of columnar epithelium at the center of the explant. (c) Villus on the left has columnar epithelial cells $(\times 10$; inset is $\times 100$ of the epithelium). Villus on the right has cuboidal to squamoid epithelium; transduced cells are present (less intensely stained cells indicated by arrows). Image to the right is $\times 100$ of the bracketed region. (d) The epithelial lineage of the cuboidal to squamoid cells observed along the bottoms of some explants was confirmed by immunofluorescent staining of a $48 \mathrm{~h}$ cultured explant for cytokeratin. Upper panel, $\times 10$ anti-cytokeratin (upper inset is $\times 40$ of columnar epithelial cells; lower inset is $\times 40$ of cuboidal cells in the monolayer along the bottom of the explant). Lower panel, $\times 10$ MOPC isotype control

of the adenoviral vector, with virtually $100 \%$ of cells along the migrating edge being transduced after $48 \mathrm{~h}$ incubation at MOI of 1000 (Figure 2a). These differences were quantified using bioluminescence imaging after
Ad5CMV-luc incubation. As seen in Figure 2b, at the MOI of 1000 there were significantly increased photon counts for wounded monolayers compared to nonwounded monolayers $(60.97 \pm 3.41$ vs. $40.04 \pm 6.05$ fold untransduced control, $p<0.05)$.

\section{Adenoviral transduction in the 'fence' system}

X-Gal staining after Ad5CMV-betaGal transduction showed a similar transduction pattern to that seen in the wounded monolayer system. When monolayers were transduced in their confluent, non-migrating state ('fence' on) there were few transduced cells scattered throughout the culture with only a rare transduced cell observed at the culture edge (Figure 3a, bottom row). When monolayers were transduced in their migrating state (after 'fence' removal) we saw a much higher number of stained cells (Figure 3a, top row). Transduced cells were localized mainly on the migrating edge of the culture. There was increased transduction at $48 \mathrm{~h}$ compared to $24 \mathrm{~h}$ (Figure 3a) with virtually $100 \%$ transduction of cells along the leading edge after $48 \mathrm{~h}$ at MOI 1000 (shown at lower magnification, Figure $3 \mathrm{~b}$ ).

Transduction efficiency was quantified using bioluminescence imaging after Ad5CMV-luc infection. There was a time- (24 vs. $48 \mathrm{~h}$ ) and dose-dependent (MOIs of 0 , 100,1000 ) increase in transduction efficiency (Figures $4 \mathrm{a}$ and $4 \mathrm{~b}$ ) for both the non-migrating and migrating state of the monolayer. At corresponding MOIs, the bioluminescent activity observed was much higher in expanding monolayers. Furthermore, photon emission patterns resembled the pattern that was seen with X-Gal staining, in that light emission was higher around the perimeter of the culture (Figure 4c). The effect was again more pronounced at the high MOI of 1000 (Figure 4c, bottom left well). The effect of cell proliferation on transducibility was studied at the intermediate MOI of 200. As shown in Figure 4d, mitomycin C pre-treatment to arrest cell proliferation in expanding monolayers did not affect transduction efficiency. The difference between expanding and non-expanding monolayers was consistent with the previous experiments.

\section{Apical vs. basolateral adenoviral transduction in Caco-2 monolayers}

We compared differences in transduction by Ad5CMVluc(loxP) after apical vs. basolateral application to Caco-2 monolayers grown on collagen-coated culture inserts. At all MOIs tested apical transduction, while limited, was 4-7-fold higher than basolateral (Figure 5a). Similar results were obtained with cells grown on uncoated inserts (not shown).

When cells were transduced apically at a MOI of 200 with the Ad5CMV-luc(loxP), EGTA pre-treatment resulted in a $70 \%$ increase in bioluminescence activity 
(a)
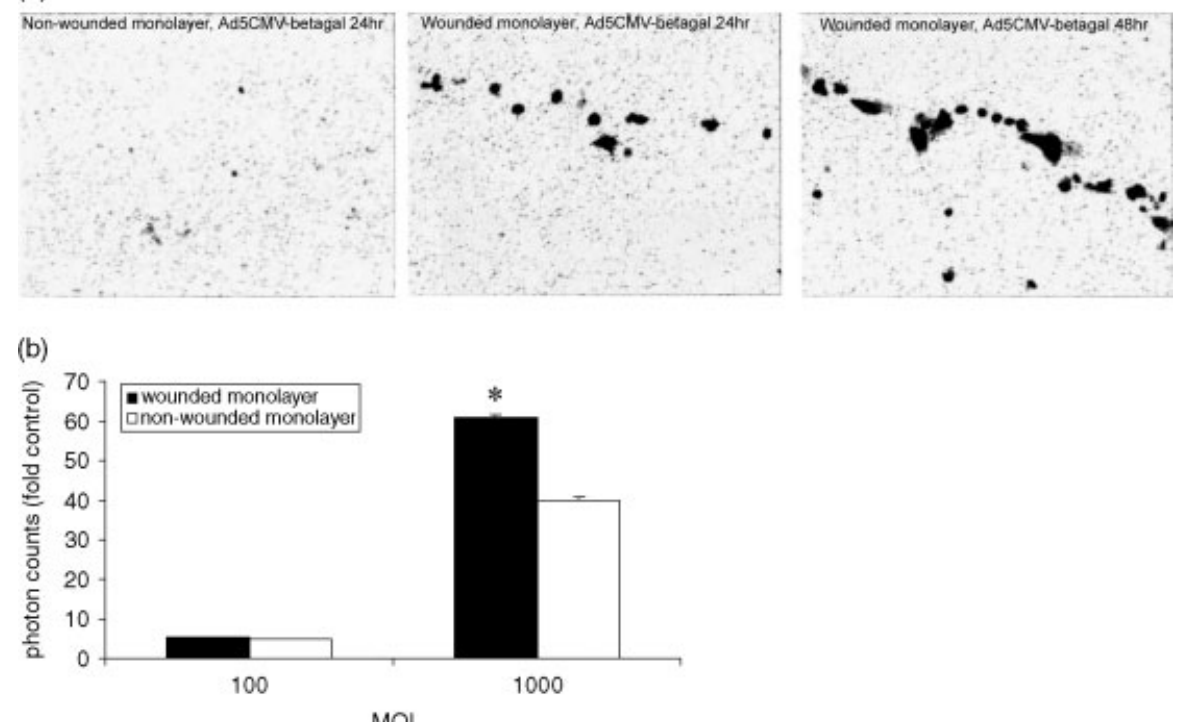

$\mathrm{MQI}$

Figure 2. Transduction of wounded vs. non-wounded Caco-2 monolayers. (a) X-Gal staining. Wounded Caco-2 monolayers were exposed to Ad5CMV-betaGal $48 \mathrm{~h}$ after wounding at a MOI of 1000. After $2 \mathrm{~h}$, additional maintenance medium was added and infection was allowed to occur for up to $48 \mathrm{~h}$. Parallel non-wounded monolayers were likewise transduced. Transduction was assayed by X-Gal staining. (b) Bioluminescence activity. Data are mean \pm SEM of photon counts (as fold untransduced control) of wounded (solid bars) and non-wounded (open bars) monolayers after $48 \mathrm{~h}$ of total incubation time with Ad5CMV-luc; ${ }^{*} p<0.05$, between wounded and non-wounded monolayers at same MOI; $n=4$

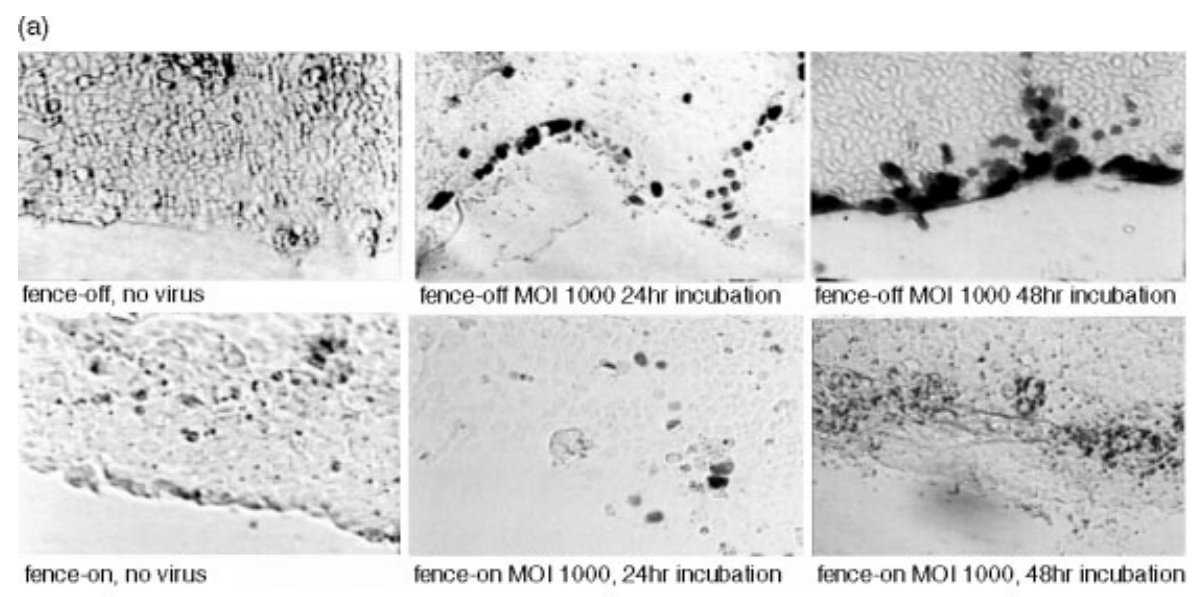

(b)
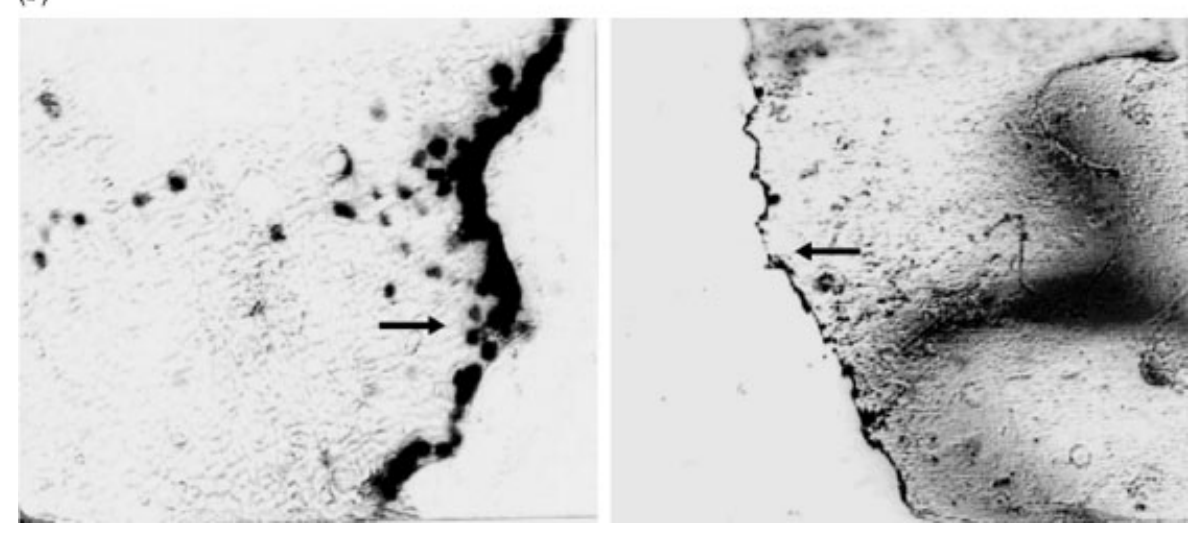

Figure 3. (a) X-Gal staining of expanding ('fence' off, upper row) and non-expanding ('fence' on, lower row) monolayers utilizing the 'fence' system. Caco-2 monolayers were exposed to Ad5CMV-betaGal at a MOI of $1000 \mathrm{for} 2 \mathrm{~h}$ at $37^{\circ} \mathrm{C}$. Additional maintenance medium was added to the cells and infection was allowed to occur for 24 or $48 \mathrm{~h}$. Cells on the edge of expanding monolayers stained blue. (b) X-Gal staining of expanding ('fence' off) monolayers as seen at lower magnification. Two different magnifications are shown. Virtually $100 \%$ of cells on the migrating edge stained blue 
(a)

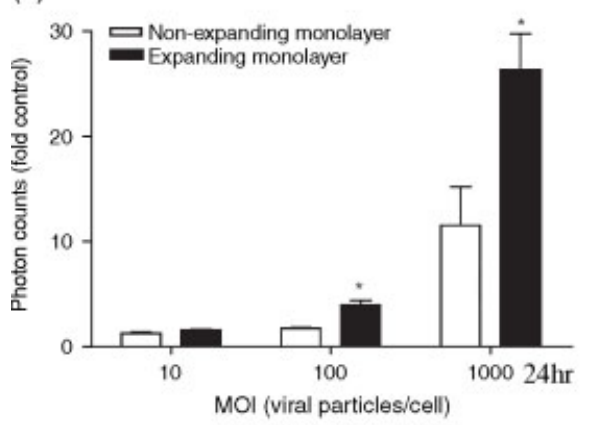

(c)

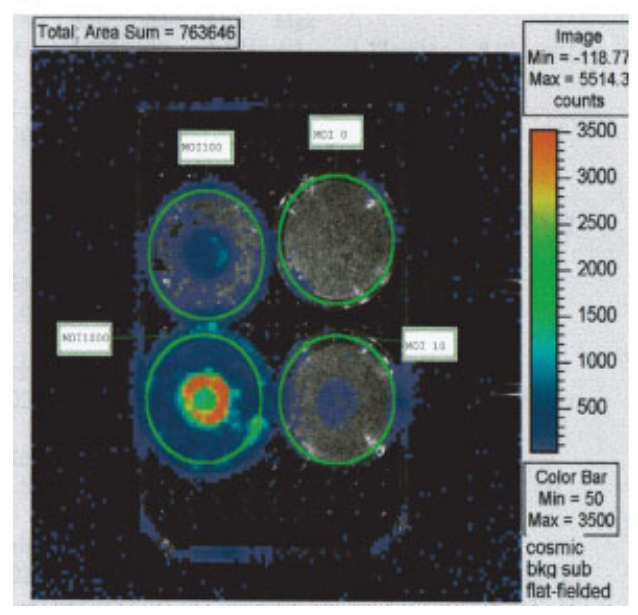

(b)

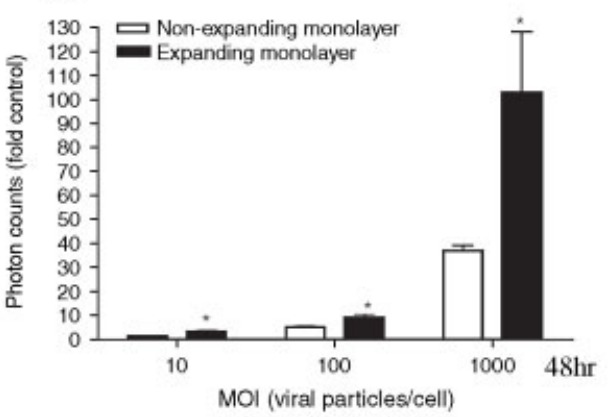

(d)

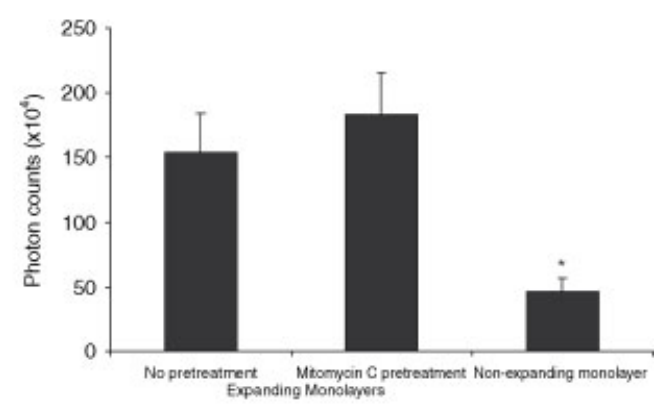

Figure 4. ( $\mathrm{a}, \mathrm{b})$ Bioluminescence activity in non-expanding ('fence' on, open bars) and expanding ('fence' off, solid bars) monolayers transduced with Ad5CMV-luc vectors utilizing the 'fence' system. Caco-2 monolayers were exposed to Ad5CMV-luc for $2 \mathrm{~h}$ at $37^{\circ} \mathrm{C}$. Additional maintenance medium was added to the cells and infection was allowed to occur for 24 (a) or $48 \mathrm{~h}$ (b). Data are mean \pm SEM of photon counts (as fold untransduced control); $n=4-5 ;{ }^{*} p<0.05$ between expanding and non-expanding monolayers at the same MOI. (c) Bioluminescence imaging of expanding ('fence' off) Caco-2 monolayers utilizing the 'fence' system. (d) Effect of mitomycin $\mathrm{C}$ pre-treatment on transduction efficiency of expanding monolayers. Confluent monolayers were pre-treated with $20 \mu \mathrm{g} / \mathrm{ml}$ mitomycin $\mathrm{C}$ for $2 \mathrm{~h}$ [17] and then allowed to expand for $24 \mathrm{~h}$. Cells were transduced with a $1: 1$ mixture of Ad5CMV-luc(loxP)/Ad5CMV-betaGal at MOI of 200. After $2 \mathrm{~h}$ additional maintenance medium was added to the cells and infection was allowed to occur for $48 \mathrm{~h}$. No significant difference was observed between monolayers pre-treated with mitomycin $\mathrm{C}$ and untreated monolayers. Data are mean \pm SEM of photon counts, $n=4 ;{ }^{*} p<0.05$, between expanding and non-expanding monolayers

(204 \pm 8.63 vs. $120.3 \pm 5.53$, mean of photon counts fold untransduced control \pm SEM of 3 replicates, $p<$ 0.01) (Figure 5b). Transduction by the non-CAR-binding Ad5SHORT vector was much less efficient, and no increase was observed with EGTA pre-treatment.

\section{Transduction inhibition experiments}

When expanding Caco-2 cell monolayers were preincubated with an anti-CAR antibody (RmcB; 1:50 dilution of ascites fluid) and subsequently transduced with Ad5CMV-luc(loxP)/Ad5CMV-betaGal at MOI 200, we observed a $36.5 \%$ decrease in transduction efficiency (Figure 6a). Pre-incubation with a $0.4 \mathrm{mM}$ solution of the RGD peptide resulted in an $18.3 \%$ reduction in transduction efficiency (Figure 6a). Pre-incubation with anti-CAR antibody (1:50 dilution of ascites fluid), followed by transduction at the high MOI of 1000, resulted in $39.4 \%$ reduction in transduction efficiency (Figure 6b). However, pre-incubation with the $0.4 \mathrm{mM}$
RGD peptide did not affect adenoviral transduction at this MOI; a significant reduction in transduction (45.4\%) was seen when the concentration of the RGD peptide was increased to $1 \mathrm{mM}$ (Figure 6b). Identical blocking experiments were performed using nonexpanding monolayers which represent fully differentiated Caco- 2 cells. At the MOI of 200, pre-incubation with $1: 50 \mathrm{RmcB}$ ascites fluid reduced transduction levels by $32.2 \%$ (Figure 6c). We noted no inhibition of transduction by the low concentration $(0.4 \mathrm{mM})$ of the RGD peptide. These results were confirmed in experiments with differentiated Caco- 2 monolayers grown on collagen-coated cell culture inserts, where RmcB pre-incubation resulted in a similar degree of transduction inhibition while the RGD peptide had a negligible effect (data not shown). However, when the MOI was increased to 1000 , neither pre-incubation with the anti-CAR monoclonal antibody or the high concentration of the RGD peptide managed to block transduction (Figure 6d). 

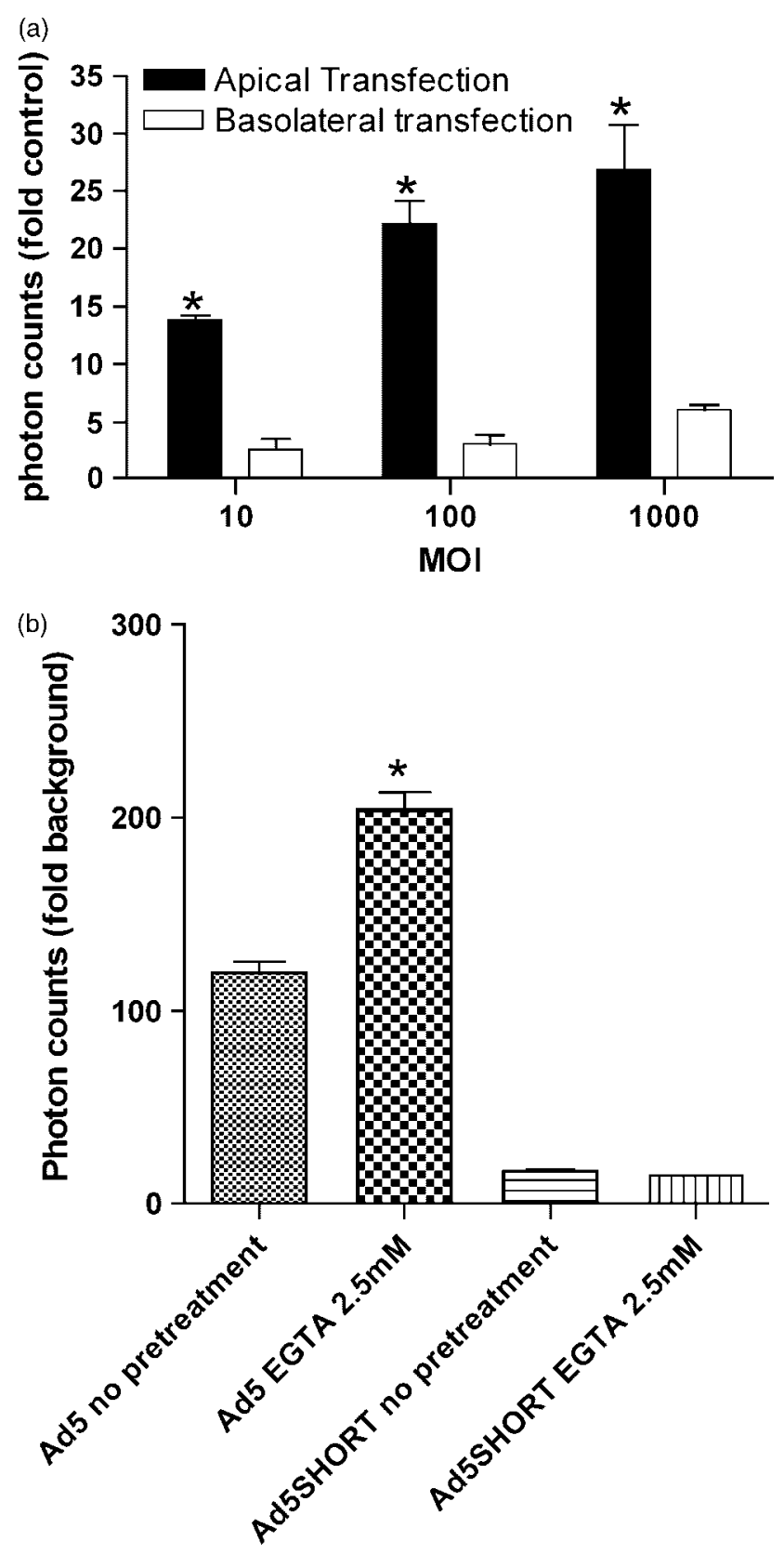

Figure 5. Difference in apical and basolateral adenoviral transduction of differentiated Caco-2 cells after (a) direct application of the virus to the apical or basolateral surface and (b) apical application of the virus after disruption of the tight junctions with EGTA pre-treatment. Caco-2 cells were grown in Transwell inserts and allowed to form a fully differentiated monolayer. Medium was aspirated and new medium containing the Ad5CMV-luc(loxP) vector at the desired MOI was added on the apical or basolateral side of the monolayer. Basolateral transduction was carried out by inverting the inserts. To disrupt the tight junctions, $2.5 \mathrm{mM}$ EGTA in DMEM was added to both the apical and basolateral chambers for $45 \mathrm{~min}$ at $37^{\circ} \mathrm{C}$ prior to virus application. Adenovirus transduction (MOI 200) was allowed to proceed for $2 \mathrm{~h}$ at $37^{\circ} \mathrm{C}$ at which point medium was aspirated, replenished with fresh medium, and cells were returned to the incubator. Luminescence activity was assayed after $48 \mathrm{~h}$ and is expressed as: (a) mean \pm SEM of photon counts (as fold untransduced control), ${ }^{*} p<0.05$, between apical and basolateral transduction at the same MOI, $n=3$ and (b) mean \pm SEM of photon counts (as fold background luminescence), ${ }^{*} p<0.05$, between pretreated and unpretreated cultures, $\mathrm{n}=3$
Transduction studies with Ad5/Ad41 chimeric vectors expressing the short fiber protein

When non-CAR-binding Ad5SHORT vectors were applied to systems of wounded/migrating Caco-2 cells we noticed a dramatic decrease in transduction efficiency as compared to standard Ad5 vectors. Quantified as bioluminescent activity and shown in Figure 7 for the 'fence' system, at the three MOIs tested $(10,100,1000)$ the chimeric vector resulted in 3.5-, 16.5- and 8.8fold fewer photon counts (fold untransduced control), respectively. The reduced transduction efficiency of these vectors was also confirmed with X-Gal staining, which showed a dramatic decrease in transduced migrating (repairing) cells (data not shown).

\section{Immunofluorescence studies}

CAR staining was observed in the apical membrane of enterocytes in the intestinal explants (Figure 8a). No difference in intensity or localization of CAR immunofluorescent staining was appreciated between columnar enterocytes and attenuated epithelial cells. MOPC isotype controls were negative.

In the Caco-2 cell 'fence' system (Figure 8b), immunofluorescent staining for CAR in non-permeabilized expanding monolayers ('fence' off, upper panel) was observed in areas of the migrating edge, with limited staining in confluent regions of the cultures. Nonpermeabilized non-expanding monolayers ('fence' on, not shown) showed limited staining throughout. In permeabilized expanding monolayers ('fence' off, middle and lower panels) staining was observed in confluent as well as migrating cells. While confluent areas of the culture showed prominent membrane staining (lower portion of middle panel), staining of cells in the migrating edge (lower panel and upper region of middle panel) appeared to be largely cytoplasmic or perinuclear, with fine membrane staining also present. An intervening region of poorly stained cells was also observed (center portion of middle panel). In contrast, permeabilized confluent monolayers ('fence' on, not shown) showed prominent membrane staining throughout. Omission of primary antibody or staining with a MOPC isotype control resulted in weak background levels of fluorescence.

\section{Discussion}

A major obstacle to successful implementation of adenoviral vectors in gastrointestinal gene delivery is the low transducibility of mature intestinal epithelial cells. This study, utilizing human endoscopic small intestinal biopsies and in vitro models of intestinal wound healing, demonstrates that wounded intestinal epithelial cells are much more susceptible to transduction by commonly used 

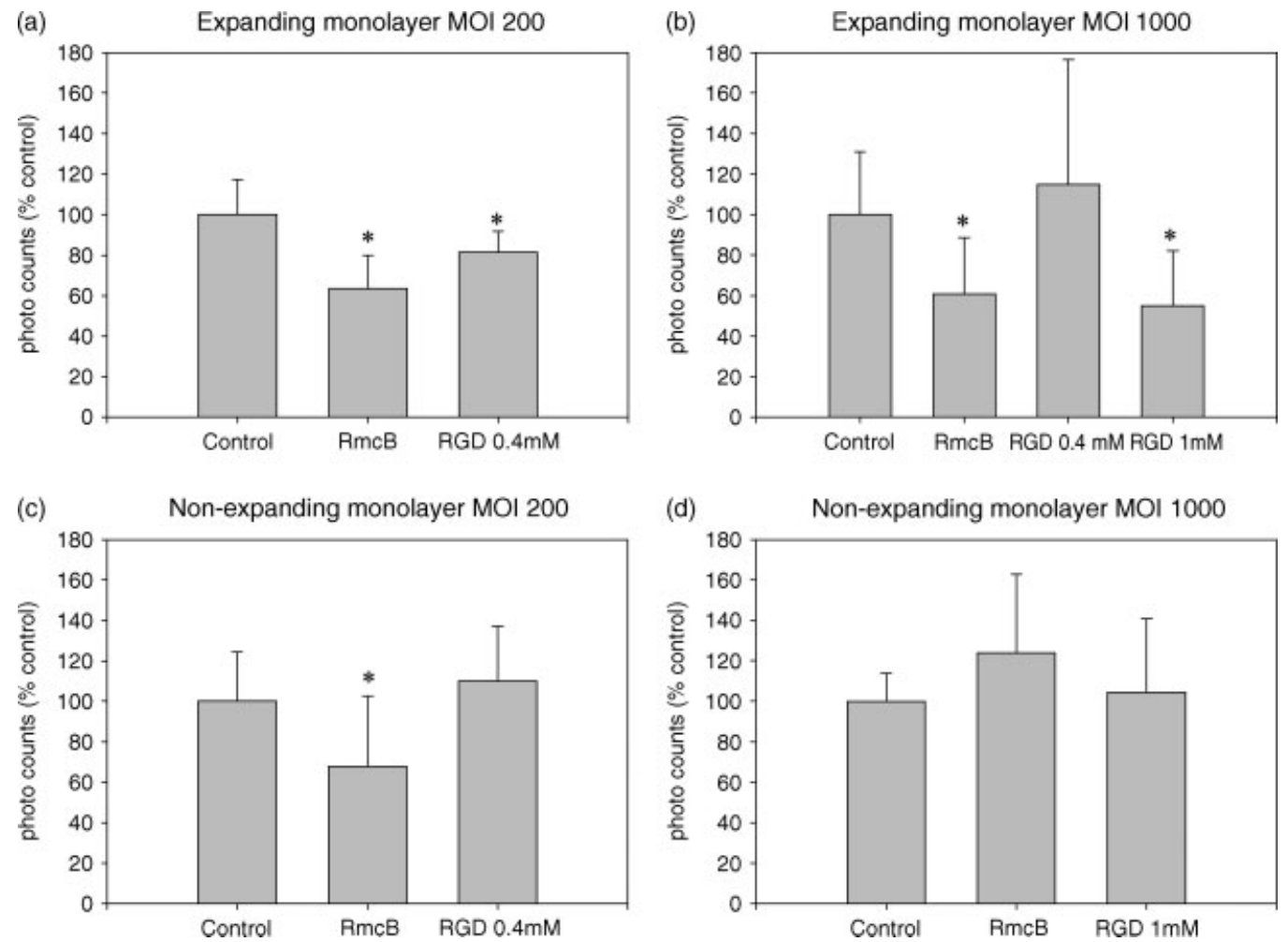

Figure 6. Transduction inhibition in (a) expanding ('fence' off) monolayers at MOI of 200, (b) expanding ('fence' off) monolayers at a MOI of 1000, (c) non-expanding ('fence' on) monolayers at a MOI of 200, and (d) non-expanding ('fence' on) monolayers at MOI of 1000. Caco-2 cell monolayers grown using the 'fence' system were pre-incubated for $2 \mathrm{~h}$ at room temperature with the following blocking solutions: 1:50 dilution of RmcB ascites fluid, GRGDSP $0.4 \mathrm{mM}$ and GRGDSP $1 \mathrm{mM}$. Subsequently, cells were transduced with either Ad5CMV-luc(loxP) or Ad5CMV-luc(loxP)/Ad5CMV-betaGal for $2 \mathrm{~h}$ at $37^{\circ} \mathrm{C}$. Luminescence activity was assayed after $48 \mathrm{~h}$ and is expressed as mean \pm standard deviation (SD) of photon counts (as \% unpretreated control); the error bar for the control represents SD of photon count measurements. ${ }^{*} p<0.05$, compared to non-blocked monolayers; $n=4-6$

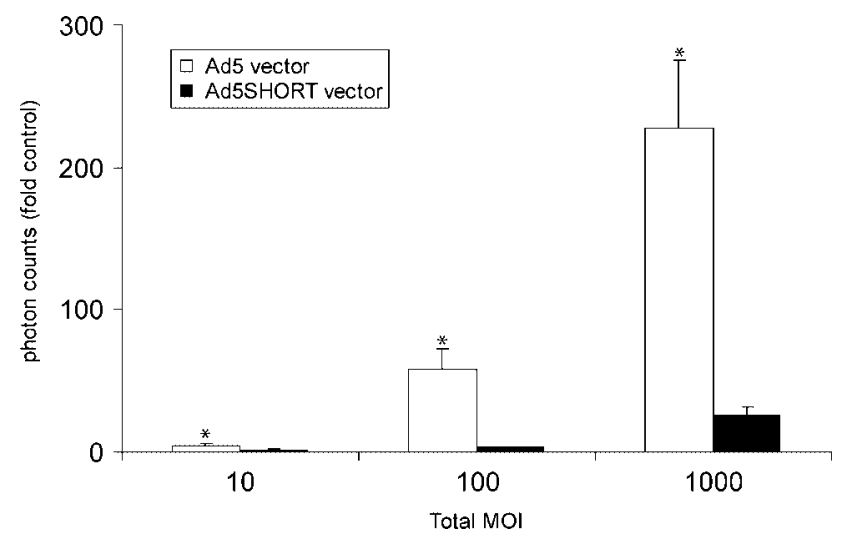

Figure 7. Differences in transduction efficiency of normal and modified Ad5 vectors applied to expanding Caco-2 monolayers utilizing the 'fence' system. Expanding ('fence' off) Caco-2 monolayers were exposed to $1: 1 \mathrm{mix}-$ tures of Ad5CMV-luc(loxP)/Ad5CMV-betaGal or Ad5SHORT-luc/ Ad5SHORT-betaGal for $2 \mathrm{~h}$ at $37^{\circ} \mathrm{C}$. Additional maintenance medium was added to the cells and infection was allowed to occur for $48 \mathrm{~h}$. Data are mean \pm SEM of photon counts (as fold untransduced control) after Ad5 (open bars) and Ad5SHORT (solid bars) administration, ${ }^{*} p<0.01$, between the two vectors at the same MOI; $n=4-5$

adenoviral vectors and might represent a valid target for the delivery of therapeutic genes to the intestine. The striking increase in transducibility occurs at the leading edge of epithelial cell migration and does not appear to be related to cell proliferation. We demonstrated a significant role of CAR in the increased transducibility of these migrating cells. For these cells, CAR appears to have increased accessibility even to apically applied adenoviral vectors, an observation contrary to previously published reports on other epithelial cell types [11,23].

Mature, differentiated enterocytes appear to be resistant to transduction by commonly used adenoviral vectors $[5,6]$. The same low levels of transduction have been reported for other epithelial cell types such as airway epithelial cells [11,24-26]. Studies utilizing Caco-2 cells suggest that the decrease in integrin expression as cells differentiate is responsible for the low transduction efficiency $[4,5]$. For airway epithelium, the low transducibility has been attributed to the absence of CAR on the apical cell membrane $[11,25]$. Furthermore, it was recently demonstrated that CAR acts as an adhesion molecule mediating homotypic cell-cell contacts, being localized in the apical junction complex helping maintain epithelial integrity $[23,27]$. To our knowledge CAR expression has not been studied in intestinal epithelial cells.

Although it is clear that healthy intestinal epithelium offers a poor target for adenoviral vectors, this might not be the case with inflamed or wounded intestinal tissue. Restituting or healing intestinal epithelium occurs in a variety of clinical settings from foreign body or caustic 

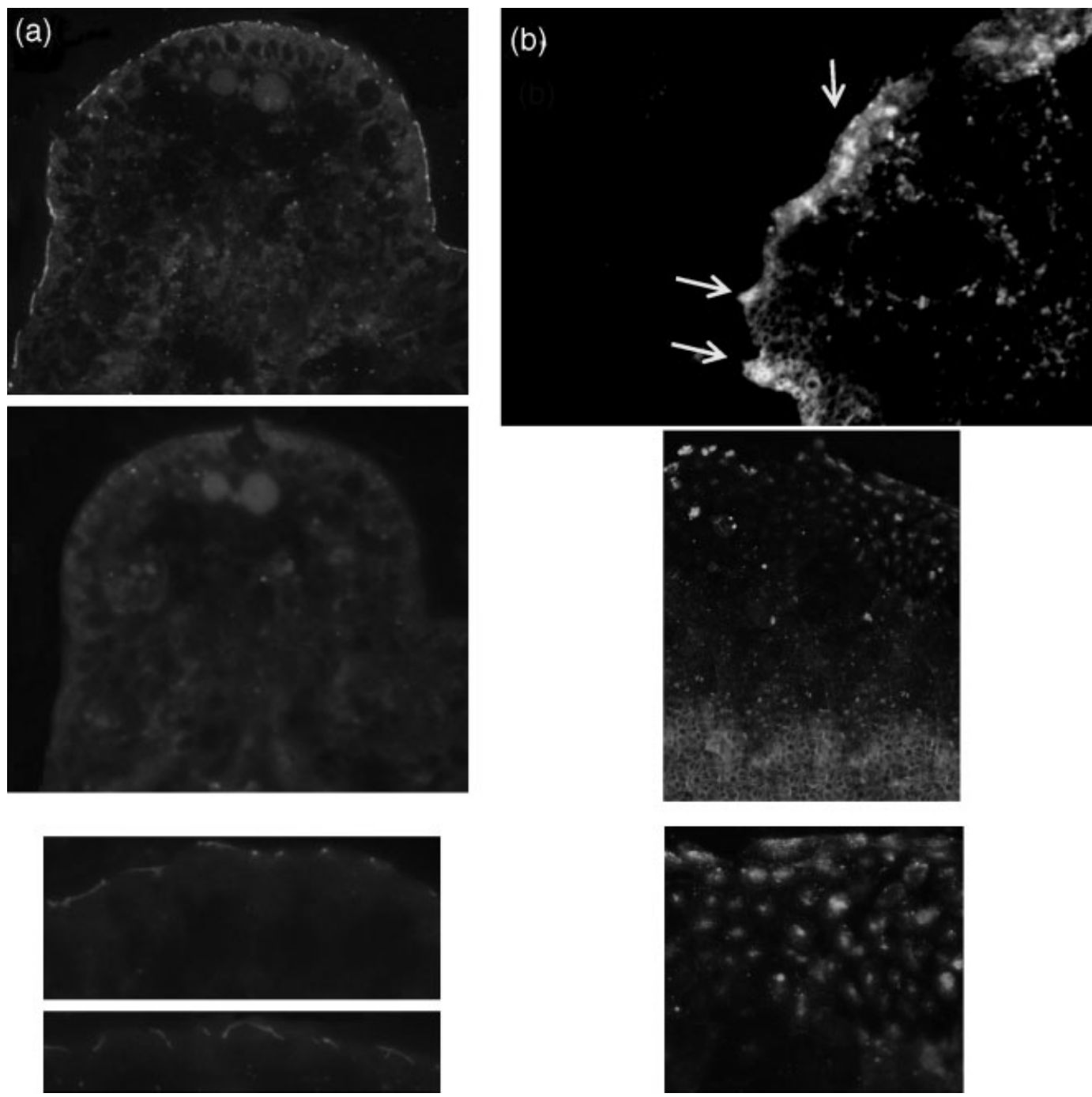

Figure 8. CAR immunofluorescence. (a) Intestinal biopsies. Villus stained with anti-CAR (upper panel, $\times 40$ ); MOPC isotype control (second panel, $\times 40$ ). Enterocyte staining: columnar cells (third panel, $\times 100$ ); cuboidal cells (fourth panel, $\times 100$ ). (b) Caco-2 cell expanding monolayer ('fence' off) in the 'fence' system. Non-permeabilized monolayer (upper panel, $\times 20$ ); arrows indicate areas of increased staining along the migrating edge. Permeabilized monolayer (middle panel, $\times 20$; lower panel, $\times 40$ )

ingestion, to viral gastroenteritis, to chronic inflammation associated with Crohn's disease. Evidence for increased transducibility of damaged intestinal epithelium exists as intrarectal Ad5 administration resulted in higher transgene expression levels in mice with colitis compared with normal mice [28].

Utilizing an organ culture model, we studied transduction of intestinal epithelium of human endoscopic small intestinal biopsies. Human intestinal explants [29] have been used for a variety of investigations including the effect of insulin on epithelial cell proliferation [30] and the synthesis of brush border membrane proteins [31]. We noted that shortened epithelial cells at the edges of explants had a higher rate of transduction by Ad5CMVbetaGal than did epithelial cells that had maintained a columnar morphology (Figure 1). In addition, epithelial cells in damaged areas of epithelium from patients with inflammatory bowel disease are transduced more readily than intact epithelium [16]. The monolayer formation along the lower surface of explants by less differentiated migrating cells is likely analogous to 'outgrowths' of similar poorly differentiated epithelial cells from explants of intestine, nasal polyp, and other tissues when the explants are cultured directly on collagen-coated dishes [32,33]. Explant outgrowths have been considered to be a model of epithelial regeneration [33]. These data suggest that intestinal epithelial cells with a de-differentiated phenotype, similar to that observed in restituting intestinal epithelium, might represent a better target for adenoviral vectors.

Several models in the literature use migrating or subconfluent Caco-2 cells to model wound healing [34-39]. The migration characteristics of the Caco-2 cells in these models resemble those seen in vivo [10]. Migrating through the wound as a sheet, they exhibit a less differentiated phenotype with squamous morphology, downregulation of brush border enzymes and integrin, and cytoskeleton reorganization that facilitates cell motility [10]. Two processes are involved in the expansion of the monolayers: cell migration and cell proliferation 
$[18,19]$. To better study the mechanism of the increased transduction of de-differentiated enterocytes we noted in the explant, we utilized two in vitro models of mucosal wound healing: the wounded monolayer and the 'fence'migration model.

Intestinal epithelial cells are transduced by adenoviral vectors in a dose- and time-dependent manner $[5,6]$. This dose dependence was observed for both confluent and expanding monolayers. The most striking differences in transduction efficiency were observed between confluent and expanding monolayers. Expanding monolayers showed up to 3-fold higher transducibility (Figure 4) with the majority of the transduced cells present in the migrating edge in both systems (Figures 2 and 3). Since the migrating cells represent only a small percentage of the total number of cells present in the culture, the observed differences constitute a substantial increase in transgene expression. In fact, at the high MOI of 1000, transduction efficiency of these migrating cells was almost 100\% (Figures 2 and 3). This is in sharp contrast to the low transducibility observed for confluent differentiated Caco2 cells both in these studies and in the literature. The high transducibility of this subset of Caco- 2 cells suggests that wounded intestinal epithelial cells represent a target that may allow sufficient expression of therapeutic genes delivered by adenoviral vectors.

Seidman et al. reported variations in adenoviral transducibility of lung carcinoma A549 cells during the cell cycle that were associated with changes in the expression of the virus receptor. Virus application during the $\mathrm{M}$ phase of the cell cycle resulted in higher transducibility [40]. In the 'fence' system, pre-treatment of expanding monolayers with mitomycin C, an inhibitor of cell proliferation, did not affect the transducibility of the migrating cells (Figure 4d), suggesting that the mechanism that accounts for their higher transducibility is related to changes that occur during the migration process rather than increased viral gene expression due to the proliferating stage of the cells. CAR and integrins are believed to be the two most important receptors that facilitate adenovirus entry into cells. In the case of Caco- 2 cells, a clear role of integrins in the transduction process has been documented [4] and was confirmed in our study. In our study, transduction of non-expanding monolayers was not affected by integrin blocking with the RGD peptide (Figures $6 \mathrm{c}$ and $6 \mathrm{~d}$ ). This is not unexpected given the low level of integrin expression in confluent monolayers [4,5]. The differences between these data and the slight reduction reported in the literature are probably due to different experimental protocols. We saw a clear inhibition of transduction in expanding monolayers preincubated with the RGD peptide (Figures 6a and 6b). As cells migrate, cytoskeleton reorganization takes place and integrins are redistributed to the migrating cell surface $[10,41]$, thereby making them accessible to the applied adenoviral vectors. It is worth noting that we had to increase RGD peptide concentration from $0.4 \mathrm{mM}$ to $1 \mathrm{mM}$ to achieve inhibition at the high MOI. It is likely that, as almost $100 \%$ of cells on the migrating edge get transduced with the increased viral load, a higher concentration of RGD peptide is required to observe significant blocking.

To our knowledge, our data is the first to support a role for CAR in mediating transduction of intestinal epithelial cells. CAR blocking with a monoclonal anti-CAR antibody resulted in reduction of transduction efficiency in expanding monolayers (Figures $6 \mathrm{a}$ and $6 \mathrm{~b}$ ). The level of blocking observed at the MOI of 200 was similar to that observed for non-expanding monolayers. However, at the MOI of 1000, while CAR blocking did not affect non-expanding monolayers, expanding monolayers were affected to the same extent as at the MOI of 200. We hypothesize that the reduced transduction after antiCAR $m A b$ preincubation is due to increased interactions between CAR on the surface of the migrating cells and the applied viruses. The fact that we see significant inhibition of transduction of non-expanding monolayers is a little surprising since CAR has been suggested to be localized either basally or at the tight junction complex towards the apical pole of the lateral membrane [27,42,43]. Previous studies have shown that airway epithelia [11] show higher transduction efficiency from the basolateral side. Our transduction inhibition data suggest that, in Caco-2 cells, CAR is accessible to adenovirus even after apical application of the virus (Figure 6). Furthermore, our studies comparing apical to basolateral transduction of differentiated Caco- 2 cells showed an opposite pattern to other epithelial cell lines, with significantly higher apical transduction (Figure 5). Higher apical transduction of Caco-2 cells has been previously reported [6]. Disruption of the tight junctions led to a modest increase (less than 2fold) in transduction efficiency (Figure 5), consistent with the observation in Caco- 2 cells that apical interactions between the cell surface and receptors are favored over basolateral ones. Similar treatment in airway epithelium has been reported to lead to an 8-9-fold increase in transduction efficiency [11], suggesting that, in airway epithelium, the virus selectively binds to receptors on the basolateral surface. To our knowledge, this is the first study to demonstrate that in an epithelial cell line, CAR is accessible from the apical surface. Although the overall transduction is still limited, this finding supports the concept of lumenal delivery of adenovirus to the intestine via the oral route.

The results obtained with the chimeric Ad5/Ad41 vector further support a higher accessibility of CAR in cells on the migrating edge of expanding Caco- 2 cultures. Ad41 is a subgroup $\mathrm{F}$ enterotropic adenovirus with significant structural differences compared to Ad5. The most notable of these is that Ad41 particles carry two fibers of different lengths and different primary sequences, designated the long and short fiber [44]. The short fiber has been shown to be unable to bind to CAR or block adenoviral transduction in culture [45]. As a result, Ad5SHORT vectors that carry the short fiber of Ad41 on their capsid are unable to initiate transduction by binding to CAR. We observed a dramatic decrease in transduction efficiency of the chimeric vectors compared to the parent Ad5 vector 
in both confluent (Figure 5) and expanding (Figure 7) Caco-2 monolayers. In the latter, the majority of Ad5 transduction occurs in the migrating cells at the edge of the culture. As the chimeric vectors do not bind CAR, the overall level of transgene expression in expanding monolayers transduced with these vectors is significantly lower than that observed with Ad5.

Immunofluorescence studies demonstrated increased CAR immunoreactivity in the cells at the migrating edge of non-permeabilized Caco-2 monolayers as compared to areas of confluence (Figure $8 \mathrm{~b}$ ). The role of CAR in the increased transduction of the migrating cells could be due to either increased CAR expression or redistribution of existing CAR receptors on the cell surface. Permeabilized monolayers showed increased staining intensity and a somewhat different pattern of staining, with prominent membrane staining in confluent areas and increased cytoplasmic/perinuclear staining in migrating cells, which also retained fine membrane staining. Because membrane staining of differentiated Caco- 2 cells by anti-CAR was not well seen unless the monolayers were permeabilized, the epitope of the transmembrane CAR protein that is recognized by the antibody appears to reside predominantly intracellularly or in the transmembrane domain in differentiated Caco- 2 cells. The observation of prominent staining of migrating cells at the edges of non-permeabilized monolayers suggests a reorientation plus/minus redistribution of CAR protein in this cell population. The intracellular staining of permeabilized migrating cells suggests that there may also be increased CAR synthesis. Although there are no available data on Caco-2 cells, differentiated and undifferentiated airway epithelial cells have been shown to express similar levels of CAR mRNA [11]. It has been reported that, during epithelial migration, there are changes in the cellular distribution of cytoskeleton proteins and adhesion molecules, such as integrins $[10,41]$. Since CAR is a cell-cell adhesion molecule normally present at the tight junction complex, it might also be undergoing cellular redistribution thus being more accessible to viral vectors on the cell surface of the restituting cells during intestinal wound healing. A role of CAR in the migration/restitution process has been suggested in other organs including the nervous system [46], the heart [47], and the carotid artery [48].

Immunofluorescence studies in explant cultures demonstrated CAR immunoreactivity in the apical membranes of both columnar and cuboidal enterocytes. We were unable to demonstrate a difference in intensity or localization of CAR immunofluorescent staining between the columnar and attenuated epithelial cells. However, this may reflect the limitations of quantitation by this technique and the fact that the tissue was in effect 'permeabilized' by sectioning as well as by xylene deparaffinization. The lack of cytoplasmic or perinuclear CAR staining in the attenuated epithelial cells may reflect the difficulty in the explant model of capturing epithelial cells which are truly of the migrating (leading edge) phenotype.

In summary, using human intestinal biopsy cultures and in vitro models of intestinal epithelial wound healing we have demonstrated that migrating intestinal epithelial cells with a de-differentiated phenotype are transduced much more efficiently than normal, fully differentiated cells. The effect appears to be related to integrin and CAR expression by the migrating cells that is associated with the migration process and is not coupled with the proliferative state of the cells. Our data is consistent with greater accessibility of CAR on the cell surface rather than increased access of the virus to the basolateral surfaces of the cells. The involvement of integrins in transduction of migrating epithelial cells is consistent with literature data that show reorganization of the cytoskeleton and integrin redistribution during the migration process of Caco-2 cells. The novel finding here is the significant role of CAR in mediating the increased transducibility of migrating cells possibly related to receptor redistribution occurring during migration. The flattened intestinal epithelial cells of the explants and the migrating Caco- 2 cells in the in vitro models used in this study are similar to restituting intestinal epithelial cells seen in vivo in inflamed or damaged tissue. As a result, these cells might represent a therapeutic target for adenoviral vectors in intestinal diseases where healing of damaged tissue occurs, such as radiationinduced intestinal injury or inflammatory bowel disease.

\section{Acknowledgements}

We thank Jerrold R. Turner (University of Chicago) and Marc D. Basson (Wayne State University) for their help with the 'fence' system. Studies involved the services of personnel of the Vector Core Laboratory, University of Michigan, who provided the adenoviral vectors. We thank the personnel at the Center for Molecular Imaging Laboratory, University of Michigan, especially Dan E. Hall, for their help with the bioluminescence imaging studies and members of the Microscopy and Image Analysis Laboratory, University of Michigan, for their help with the fluorescence microscopy. We finally thank Joel R. Chamberlain for characterizing the chimeric Ad5/Ad41 vector. This work was supported by grants from the National Institutes of Health (RO1DK56750 to Ellen Zimmermann), the Michigan Life Science Corridor Fund (to Ellen Zimmermann), National Cancer Institute (R24CA83099 to MSAIR), and the Michigan Gastrointestinal Peptide Research Center (P30DK34933 to Vector Core Laboratory).

\section{References}

1. Horwitz MS. Adenoviruses. In Virology, Fields BN, Knipe DM, Howley PM (eds). Lippincott-Raven: Philadelphia, 1996; 2149-2171.

2. Cheng DY, Kolls JK, Lei D, Noel RA. In vivo and in vitro gene transfer and expression in rat intestinal epithelial cells by E1deleted adenoviral vector. Hum Gene Ther 1997; 8: 755-764.

3. Foreman PK, Winwright MJ, Alicke B, et al. Adenovirusmediated transduction of intestinal cells in vivo. Hum Gene Ther 1998; 9: 1313-1321.

4. Croyle MA, Walter E, Janich S, Roessler BJ, Amidon GL. Role of integrin expression in adenovirus-mediated gene delivery to the intestinal epithelium. Hum Gene Ther 1998; 9: 561-573.

5. Walter E, Croyle MA, Roessler BJ, Amidon GL. The absence of accessible vitronectin receptors in differentiated tissue hinders adenoviral-mediated gene transfer to the intestinal epithelium in vitro. Pharm Res 1997; 14: 1216-1222. 
6. Walter E, Croyle MA, Davidson BL, Roessler BJ, Hilfinger JM, Amidon GL. Adenovirus mediated gene transfer to intestinal epithelial cells as a potential approach for oral delivery of peptides and proteins. $J$ Control Release 1997; 46: 75-87.

7. Hamilton T, DeMatteo R, McClane S, Burke C, Rombeau J, Raper S. Adenoviral-mediated gene transfer to murine small intestine is more efficient in neonates than adults. J Pediatr Surg 1997; 32: 373-377.

8. Hidalgo IJ, Raub TJ, Borchardt RT. Characterization of the human colon carcinoma cell line (Caco-2) as a model system for intestinal epithelial permeability. Gastroenterology 1989; 96: 736-749.

9. Hamilton TE, McClane SJ, Baldwin S, et al. Efficient adenoviralmediated murine neonatal small intestinal gene transfer is dependent on alpha(v) integrin expression. J Pediatr Surg 1997; 32: 1695-1703.

10. Basson MD. In vitro evidence for matrix regulation of intestinal epithelial biology during mucosal healing. Life Sci 2001; 69: 3005-3018.

11. Walters RW, et al. Basolateral localization of fiber receptors limits adenovirus infection from the apical surface of airway epithelia. J Biol Chem 1999; 274: 10219-10226.

12. Gerard RD, Meidell RS. Adenovirus vectors. In DNA Cloning: A Practical Approach, Glover DM, Hames BD (eds). Oxford University Press: Oxford, 1995; 285-305.

13. Chartier C, Degryse E, Gantzer M, Dieterle A, Pavirani A, Methali M. Efficient generation of recombinant adenovirus vectors by homologous recombination in Escherichia coli. $J$ Virol 1996; 70: 4805-4810.

14. Chamberlain JR, Shaw MH, Hilfinger JM, Zimmermann EM, Roessler BJ. Recombinant adenovirus serotype switching for analysis of efficiency and route of intestinal cells entry. Gastroenterology 2000; 118: A671.

15. Schmiedlin-Ren P, Benedict PE, Dobbins WO, 3rd, Ghosh M, Kolars JC, Watkins PB. Cultured adult rat jejunal explants as a model for studying regulation of CYP3A. Biochem Pharmacol 1993; 46: 905-918.

16. Schmiedlin-Ren P, Kesisoglou F, Mapili JA, et al. Increased transduction of human intestinal epithelial cells by adenoviral vectors in inflammatory bowel disease. Inflamm Bowel Dis 2005; 11: 464-472.

17. Pratt BM, Harris AS, Morrow JS, Madri JA. Mechanisms of cytoskeletal regulation. Modulation of aortic endothelial cell spectrin by the extracellular matrix. Am J Pathol 1984; 117: 349-354.

18. Basson MD, Modlin IM, Flynn SD, Jena BP, Madri JA. Independent modulation of enterocyte migration and proliferation by growth factors, matrix proteins, and pharmacologic agents in an in vitro model of mucosal healing. Surgery 1992; 112: 299-307; discussion 307-308.

19. Perdikis DA, Davies R, Zhuravkov A, Brenner B, Etter L, Basson MD. Differential effects of mucosal $\mathrm{pH}$ on human (Caco-2) intestinal epithelial cell motility, proliferation, and differentiation. Dig Dis Sci 1998; 43: 1537-1546.

20. Artursson P, Magnusson C. Epithelial transport of drugs in cell culture. II: Effect of extracellular calcium concentration on the paracellular transport of drugs of different lipophilicities across monolayers of intestinal epithelial (Caco-2) cells. J Pharm Sci 1990; 79: 595-600.

21. Boulenc X, Marti E, Joyeux H, Roques C, Berger Y, Fabre G. Importance of the paracellular pathway for the transport of a new bisphosphonate using the human CACO-2 monolayers model. Biochem Pharmacol 1993; 46: 1591-1600.

22. Hsu KH, Lonberg-Holm K, Alstein B, Crowell RL. A monoclonal antibody specific for the cellular receptor for the group $B$ coxsackieviruses. J Virol 1988; 62: 1647-1652.

23. Cohen CJ, Shieh JT, Pickles RJ, Okegawa T, Hsieh JT, Bergelson JM. The coxsackievirus and adenovirus receptor is a transmembrane component of the tight junction. Proc Natl Acad Sci U S A 2001; 98: 15191-15196.

24. Pickles RJ, Fahrner JA, Petrella JM, Boucher RC, Bergelson JM. Retargeting the coxsackievirus and adenovirus receptor to the apical surface of polarized epithelial cells reveals the glycocalyx as a barrier to adenovirus-mediated gene transfer. $J$ Virol 2000; 74: 6050-6057.

25. Zabner J, Freimuth P, Puga A, Fabrega A, Welsh MJ. Lack of high affinity fiber receptor activity explains the resistance of ciliated airway epithelia to adenovirus infection. $J$ Clin Invest 1997; 100: 1144-1149.

26. Zabner J, Zeiher BG, Friedman E, Welsh MJ. Adenovirusmediated gene transfer to ciliated airway epithelia requires prolonged incubation time. $J$ Virol 1996; 70: 6994-7003.

27. Walters R, Freimuth P, Moninger T, Ganske I, Zabner J, Welsh M. Adenovirus fiber disrupts CAR-mediated intercellular adhesion allowing virus escape. Cell 2002; 110: 789.

28. Wirtz S, Galle PR, Neurath MF. Efficient gene delivery to the inflamed colon by local administration of recombinant adenoviruses with normal or modified fibre structure. Gut 1999; 44: 800-807.

29. Eastwood GL, Trier JS. Organ culture of human rectal mucosa. Gastroenterology 1973; 64: 375-382.

30. Menard D, Corriveau L, Beaulieu JF. Insulin modulates cellular proliferation in developing human jejunum and colon. Biol Neonate 1999; 75: 143-151.

31. Bailey D, Turnbull G, Bartsch R, Begent R, Sapsford R, Ciclitira PJ. Comparative analysis of adult and fetal human small intestinal microvilli. Digestion 1997; 58: 155-160.

32. Quaroni A. Development of fetal rat intestine in organ and monolayer culture. J Cell Biol 1985; 100: 1611-1622.

33. Dupuit F, Zahm JM, Pierrot D, et al. Regenerating cells in human airway surface epithelium represent preferential targets for recombinant adenovirus. Hum Gene Ther 1995; 6: 1185-1193.

34. Nakajima M, Shinoda I, Samejima Y, Miyauchi H, Fukuwatari Y, Hayasawa H. Lactoferrin as a suppressor of cell migration of gastrointestinal cell lines. J Cell Physiol 1997; 170: 101-105.

35. Zushi S, Shinomura Y, Kiyohara T, et al. Role of prostaglandins in intestinal epithelial restitution stimulated by growth factors. Am J Physiol 1996; 270: G757-762.

36. Pereira SH, Cervante MP, Bentzmann S, Plotkowski MC. Pseudomonas aeruginosa entry into Caco-2 cells is enhanced in repairing wounded monolayers. Microb Pathog 1997; 23: 249-255.

37. Basson MD, Modlin IM, Madri JA. Human enterocyte (Caco2) migration is modulated in vitro by extracellular matrix composition and epidermal growth factor. J Clin Invest 1992; 90: $15-23$.

38. Liu YW, Sanders MA, Basson MD. Human Caco-2 intestinal epithelial motility is associated with tyrosine kinase and cytoskeletal focal adhesion kinase signals. J Surg Res 1998; 77: $112-118$.

39. Dignass AU, Tsunekawa S, Podolsky DK. Fibroblast growth factors modulate intestinal epithelial cell growth and migration. Gastroenterology 1994; 106: 1254-1262.

40. Seidman MA, Hogan SM, Wendland RL, Worgall S, Crystal RG, Leopold PL. Variation in adenovirus receptor expression and adenovirus vector-mediated transgene expression at defined stages of the cell cycle. Mol Ther 2001; 4: 13-21.

41. Stutzmann J, Bellissent-Waydelich A, Fontao L, Launay JF, Simon-Assmann P. Adhesion complexes implicated in intestinal epithelial cell-matrix interactions. Microsc Res Technol 2000; 51: 179-190.

42. Carson SD, Chapman NM. Coxsackievirus and adenovirus receptor (CAR) binds immunoglobulins. Biochemistry 2001; 40: 14324-14329.

43. Coyne CB, Bergelson JM. CAR: a virus receptor within the tight junction. Adv Drug Deliv Rev 2005; 57: 869-882.

44. Yeh HY, Pieniazek N, Pieniazek D, Gelderblom H, Luftig RB. Human adenovirus type 41 contains two fibers. Virus Res 1994; 33: $179-198$.

45. Roelvink PW, Lizonova A, Lee JG, et al. The coxsackievirusadenovirus receptor protein can function as a cellular attachment protein for adenovirus serotypes from subgroups A, C, D, E, and F. J Virol 1998; 72: 7909-7915.

46. Hotta Y, Honda T, Naito M, Kuwano R. Developmental distribution of coxsackie virus and adenovirus receptor localized in the nervous system. Brain Res Dev Brain Res 2003; 143: 1-13.

47. Ito M, Kodama M, Masuko M, et al. Expression of coxsackievirus and adenovirus receptor in hearts of rats with experimental autoimmune myocarditis. Circ Res 2000; 86: 275-280.

48. Nasuno A, Toba K, Ozawa T, et al. Expression of coxsackievirus and adenovirus receptor in neointima of the rat carotid artery. Cardiovasc Pathol 2004; 13: 79-84. 